\title{
A useful ultrasound artifact and its application - the 'twinkling sign'
}

\author{
H Lameen, MB ChB \\ $S$ Theron, MB ChB, MMed (Rad) \\ F Steyn, MB ChB \\ M Grobbelaar, $M B \mathrm{ChB}$ \\ A Mapukata, MB ChB
}

S Andronikou, MB BCh, FRCR, FCRad, PhD

Department of Radiology, Tygerberg Hospital and University of Stellenbosch

The 'twinkling sign' is described as a colour Doppler artifact in which a rapidly changing mixture of red and blue colours is displayed distal to a strongly, rough reflective structure (Figs 1 and 2). ${ }^{1}$ This probably results from complex back scatter of the ultrasound waves with prolonged pulse duration, interpreted by Doppler as movement. ${ }^{2}$ This sign is a fundamental artifact because it is well detected by the digital Doppler system which has a higher noise immunity. The focal depth minimally affects the shape of the artifact by narrowing its focal width when the calculus is out of focus. ${ }^{1}$
There is a relationship between this artifact and the morphology (surface) and the chemical composition of the calculus. Identification of the composition of the calculus can help for the management options used. $^{2}$

An artifact on other imaging modalities, which results from an error in the imaging technique, may lead to misinterpretation of the image. The 'twinkling sign' may lead to misinterpretation by suggesting vascular flow. This particular artifact has a benefit in differentiating a very small calculus from other echogenic structures in the urinary tract particularly after lithotripsy. ${ }^{1,2}$ Another application of the twinkling sign is for guiding transthoracic needle aspiration of lung and mediastinal masses. The needle is identified by using the twinkling sign (by moving the inner stylet gently). The needle tip is well located and the blood vessels are avoided. ${ }^{3}$

1. Aytac SK, Ozcan H. Effect of color Doppler system on the twinkling sign associated with urinary calculi. J Clin Ultrasound 1999; 27: 433-439.

2. Darge K. Be aware and beware of the twinkling sign. Pediatr Radiol 2005; 35: 351-352

3. Gorguner M, Misirlioglu F, Polat P, et al. Color Doppler sonographically guided transthoracic needle aspiration of lung and mediastinal masses. J Ultrasound Med 2003; 22: 703-708.
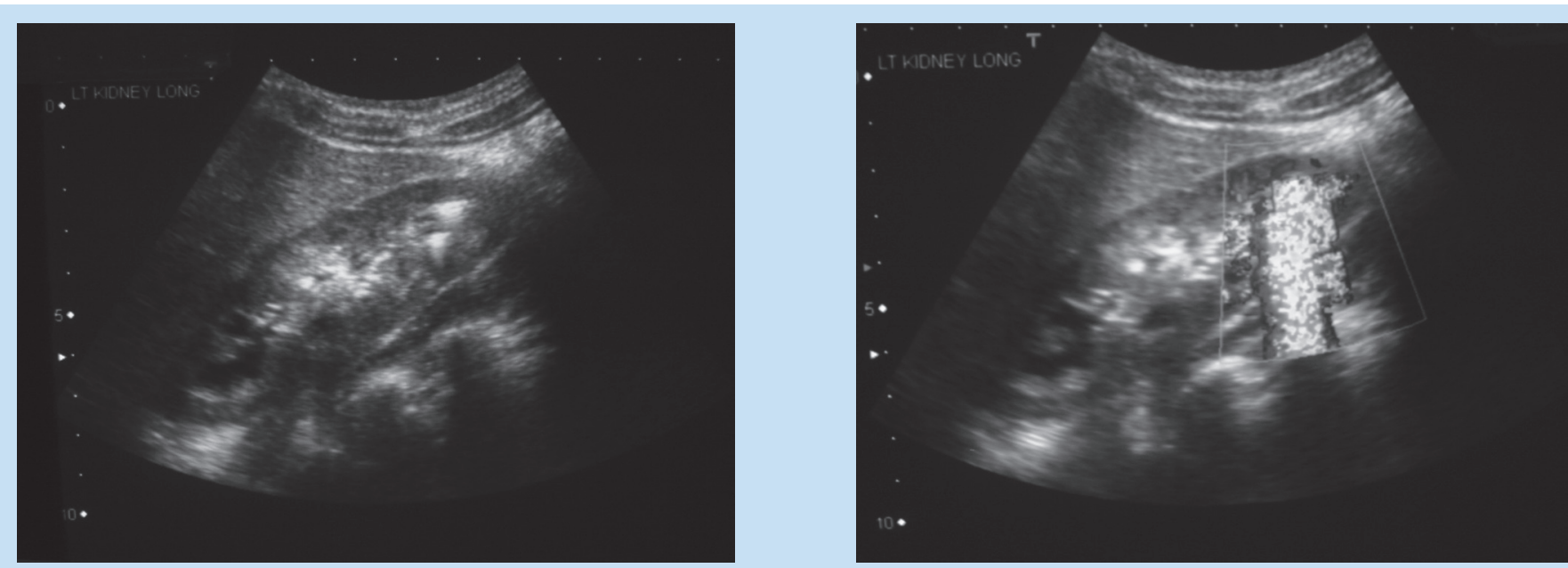

Fig. 1 (a) B- mode ultrasound of the left kidney shows two echogenic structures in the lower pole without acoustic shadowing. Applying the colour Doppler for the same kidney (b) shows multi-coloured pixels, the 'twinkling sign', distal to the echogenic structures. 